\title{
Photography as an act of collaboration
}

\author{
Rutherford*
}

The Faculty of Media and Communications, Weymouth House, Bournemouth University, Talbot Campus, Fern Barrow, Poole BH12 5BB, UK

\begin{abstract}
The camera is usually considered to be a passive tool under the control of the operator. This definition implicitly constrains how we use the medium, as well as how we look at - and what we see in - its interpretations of scenes, objects, events and 'moments'. This text will suggest another way of thinking about - and using the photographic medium. Based on the evidence of photographic practice (mine and others'), I will suggest that, as a result of the ways in which the medium interprets, juxtaposes and renders the elements in front of the lens, the camera is capable of depicting scenes, events and moments that did not exist and could not have existed until brought into being by the act of photographing them. Accordingly, I will propose that the affective power of many photographs is inseparable from their 'photographicness' - and that the photographic medium should therefore be considered as an active collaborator in the creation of uniquely photographic images.
\end{abstract}

\section{Introduction}

As a consequence (legacy) of its origins as a machine of the industrial revolution, and one that operates - like the microscope and the telescope - according to the laws of nature [the pioneer of photography Fox Talbot described it (1844) as 'The pencil of nature'], the photograph is widely considered to be an 'accurate and objective record' (Genoni 2002, 137), 'a faithful record of what has been witnessed' (Rogers 1978, 33), 'a window on reality' (Bryman 2012, 427) which describes things 'as they really are' (Ross 1982, 12) and a 'natural and truthful' account (Fosdick and Fahmy 2007, 1) of what was 'already there' (Barthes 1984, 55).

Although the capacity of photographs to lie was established very early (by providing photographic 'proof', for example, of the existence of both fairies and the Loch Ness Monster), the popular conception of photographs as reliable evidence enabled (and continues to enable) practitioners to confront the public with truths and realities many had never seen, been able to see (and, in some cases, may not have wanted to see exposed). Confronted with an 'accurate and objective record' of the horrors of war (in the photographs of Brady, Gardner, O'Sullivan) and the living and working conditions of the poor (in the photographs of Riis, Hine), these oncedistant phenomena became harder to ignore and romanticise (Gernsheim 1965, 148). As a result, photographs not only have added to our knowledge and understanding, but also have had a profound impact on our attitudes towards important social issues (Rose 2006, 23; Gernsheim 1965, 149).

*Email: rutherford@bournemouth.ac.uk 


\section{Rutherford}

This belief in the 'accuracy and objectivity' of photography meant, however, that the medium was widely dismissed as 'anti-art' (Seamon 1997, 246) due to its ability to reproduce scenes, objects and events without the need for any artistic or aesthetic training or talent by the operator (Bourdieu 1996, 77).

[A]rtists working with photography have addressed photography's claims to originality, showing those claims for the fiction they are, showing photography to be always a representation, always-already-seen. Their images are purloined, confiscated, appropriated, stolen. (Crimp 1980, 98)

I am not concerned here with whether photography is Art, but wish only to draw the reader's attention to the fact that, while there is passionate disagreement as to the merits of the images photographers produce, both sides of the debate consider and treat the camera as a passive tool under the conscious control of the operator (Bourdieu 1996; de Brigard 1995; Krauss 1984; Mellinger 1994; Moran and Tegano 2005; Price 2009; Stylianou-Lambert 2012; Urry 2002). ${ }^{1}$

\section{Talking about photography}

The use, value and implications of photographs are discussed and debated in a wide variety of applications: as scientific and medical evidence that give us a window onto previously invisible worlds; as news or documentary descriptions of the world as others live it; as emotive propaganda that tempt us with glimpses of the sugar-plumb world available to consumers of the sponsor's products; as family snapshots that record the world as we will subsequently remember it and, in books and galleries, as fragments-of-the-world made special by the photographer's attention.

In all of these contexts, however, photographs are implicitly understood to be the product of the interaction of only three factors (Smith 1999; Rogers 1978, 33): the photographer's intention (what we want to achieve), the photographer's expertise (our capacity to manipulate the camera controls and the means of interpretation in pursuit of a desired result) and the appearance and/or behaviour of (what I call) the Things in Front of the Lens (the physical phenomena recorded, as well as their juxtaposition in three-dimensional space at that moment and from that perspective).

Bordieu (1993) has argued that, because our knowledge of the conditions under which work was produced (and conceived) comes only after the fact and takes place in the domain of rational thought and communication, the ways in which we use language to describe the finished product (the 'opus operatum') often conceals the actual process ('the modus operandi') of its creation (Bordieu 1993, 158). As a consequence, the traditional conception of the role and function of the camera/ medium as a passive tool under the conscious control of the operator has shaped both photographic practice (what, how and why we photograph) as well as what we see in the results.

Our language, and the way in which we use it, both reflects and shapes/reinforces our perception of the world. As Boulding (1961) noted, our internalised conceptions (our mental 'images') determine what we believe something 'is' and, by extension, what it is 'for'. General Semantics (Korzybski 1933, Hayakawa 1949) demonstrates that that the syntactic structure of language with which we symbolically represent ('mentally map') the world defines (from the Latin 'to draw a line around') our 
conceptions of both objects and actions. For example, when we use the phrase 'You made me angry', we implicitly locate - and reinforce our belief in - an external cause for our distress, thereby blinding ourselves to its true origins within. Consider too, the profound differences in the 'mental maps' implied (and reinforced) by change of verbs in two descriptions of the sex act: 'The man puts his penis' and 'The woman takes the man's penis'.

[T]hinking also follows a network of tracks laid down in the given language, an organization which may concentrate systematically upon certain phases of reality [...] and systematically discard others. The individual is utterly unaware of this organization and is constrained completely within its unbreakable bonds. (Whorf 1952, 177)

Accordingly, behind even apparently simple and uncontroversial words lie patterns and systems of thought and judgement that lead us to project particular (and sometimes very peculiar) interpretations of actions and the nature of things. By recognising and reflecting on the hidden implications of the way in which we use language, we can transform our understanding.

As photographers and as viewers, if we think of (define) photographs as having been 'taken' [or 'purloined, confiscated, appropriated, stolen' (Crimp 1980, 98)] we impose on ourselves the perspective that the qualities, features and/or characteristics of the image from which it derives its merit were already 'out there' in front of the lens and that the camera is a passive tool used to 'capture' them. For the same reason, by thinking of the camera as a passive tool, capable of recording only what is 'out there', we implicitly (and imperceptibly) constrain our ability to recognise what it describes. For the same reason, I take issue with the term 'the subject of the photograph' and its implicit inference that what the photograph is 'about' (its 'topic' or 'what it shows us') is separate - and separable - from the way in which the medium interprets, depicts or renders the Things in Front of the Lens.

While numerous photographs are indeed 'taken' (such as those of meticulously arranged still life and studio photographs, and whatever it is that Cindy Sherman is up to), I submit that it is often both more accurate - and, for practitioners, a valuable way in which to loosen the conceptual bounds that restrict our imaginations - to describe (and thereby force ourselves to think of) photographs as 'made', not 'taken'. By doing so, we can begin to re-IMAGinE ${ }^{2}$ the medium of photography as an active collaborator in the creation of the resulting image - and one whose contribution is the result of neither intention, expertise nor the Things in Front of the Lens.

By adopting the term 'making' photographs, we are encouraged to see the result as a collaboration with the modus operandi of the process in the creation of an image which did not (and sometimes could not) exist 'out there', but which was brought into being by the way in which the medium interpreted and rendered the Things in Front of the Lens at that moment and from that perspective. The resulting photograph is therefore both the record and the product of the way in which medium 'maps' (pace Korzybski) both time and space.

In Titarenko's series City of Shadows, the modus operandi of the medium has transformed the Things in Front of the Lens to produce results which are uniquely 'photographic' (Figure 1). 


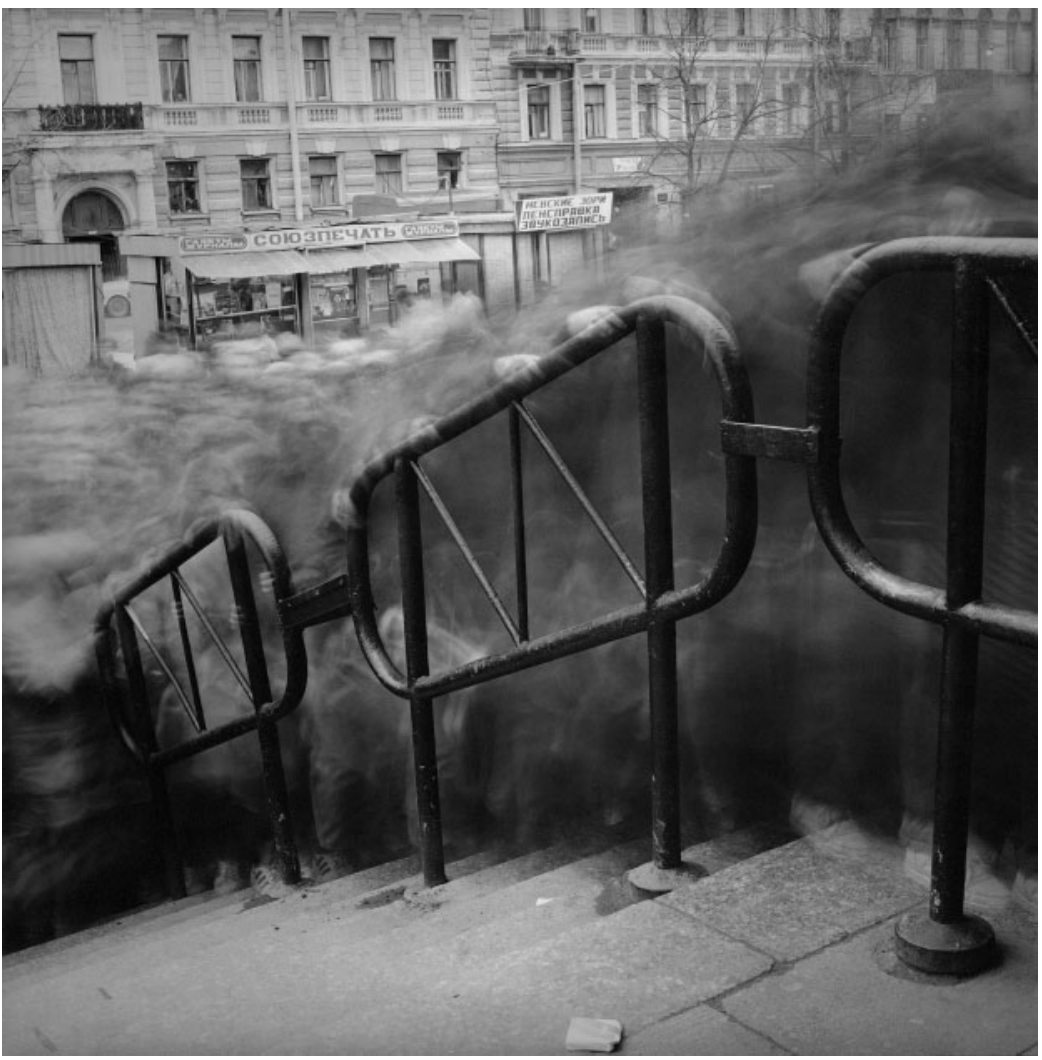

Figure 1. Untitled (Crowd 2), St. Petersburg, Russia 1993 (from 'City of Shadows' series) (C) Alexey Titarenko, Courtesy of Nailya Alexander Gallery, New York.

Although the (often unanticipable) contribution of the medium in the creation of photographs has previously been noted by some well-renowned practitioners:

I photograph to find out what something will look like photographed [...] the photograph isn't what was photographed, it's something else. (Garry Winogrand, cited by Sontag 1973, 197 and Diamonstein 1981-82)

I never have taken a picture I've intended. They're always better or worse. You don't put into a photograph what's going to come out. Or what comes out is not what you put in. The camera is 'recalcitrant'. You may want to do one thing and it's determined to do something else. (Diane Arbus 1972, 11, 14-15)

I fully agree with [you about giving] photography the chance to participate in the production and creating of an interesting picture. Often I work in this way [so] that I don't know what will be on the film. (Michel Szulc Krzyanowski, personal correspondence 1988)

The definition of the medium as an active collaborator put forward here has not, to my knowledge, been explicitly investigated. A search via Google Scholar ${ }^{\mathrm{TM}}$ using various permutations of the phrase 'photography as collaborator' produced hundreds of results - but none in which the term 'collaboration' refers to the meaning or application suggested here. 


\section{Methodology and evidence}

Based on the evidence of photographic practice (mine and others'), this article will suggest that, as a result of the ways in which the medium interprets, juxtaposes and renders the Things in Front of the Lens at that moment and from that perspective, photographs are capable of depicting scenes, events and moments that did not exist and could not have existed until brought into being by the act of photographing them. If so, I submit that the affective power of many photographs is inseparable from their 'photographicness', and that, as a consequence, the photographic medium should be deemed to be an active collaborator in the creation of uniquely photographic images.

To demonstrate the existence of this phenomenon, I will briefly consider three aspects of the posited active (act of) collaboration by the medium in the creation of photographs:

(1) That an essential feature or characteristic of many powerful photographs is the direct result of the contribution of the photographic medium (their 'photographicness')

(2) That the active (act of) contribution by the photographic medium can result in the creation of images that did not exist and could not have existed until brought into being by the act of photographing them

(3) That the mechanical properties of the photographic medium can offer our subconscious an unmediated means of expression as a way to increase selfknowledge

The first assertion will be established by the content analysis of 12 photographs, several of which are well known within the discipline. While the methodologies by which visual materials are usually examined seek to establish the social meaning of such evidence (Gray and Malins 2004; Rose 2006), this article is concerned with the way in which the medium of photography produces images, not the meaning we make of (or find in) them. Accordingly, in applying content analysis, the 12 photographs will be considered in terms of their uniquely 'photographic' features - including: the assumption that they offer an 'objective' and 'truthful' record and representation of elements, the capacity of elements to be 'blurred' during exposure, the juxtaposition of elements within the frame, the compression of three-dimensional space onto a flat plane and the extraction of a 'moment' from (what we experience as) a chronological continuum.

The second and third assertions will be supported by the application of grounded theory and critical refection on the accumulated evidence provided by the results of my photographic practice in which [as per Alvesson and Sköldberg's notion of Abduction $(2009,4)]$ the thesis and data have been successively reinterpreted in light of one another.

This is consistent with Silverman's $(2010,235)$ model of grounded theory in which thoughtful, critical refection on the accumulating data (the photographs) leads to the development (and subsequent refinement) of categories through which the meaning, significance and implications can then be identified. Consistent with Silverman's model, the central insight suggested by the categorisation of the data (that the merits or value of the results are dependent on the medium in which they were created) has relevance beyond the original context, and with implications for other technological media, including cinematography, video and digital art. 
That an essential feature or characteristic of many powerful photographs is their 'photographicness'

Picture in your mind's eye one of your favourite photographs; now imagine the same image rendered as, say, a pen-and-ink sketch, or a watercolour. If the image loses nothing of its power in the translation, I submit that it is not a successful photograph.

Just as Picasso, Pollock and others rejected the 'the pre-modernist objective of naturalistic representation' in favour of an exploration of 'painting's formal, material means of expression' (Harris 2006, 257) - in other words, they 'painted painting' - I submit that the essential feature of a successful photograph (one which offers an alternative interpretation of either the events it depicts or the conventions of representation) is its 'photographicness'. In other words, it is as much 'about' photography and its 'way of seeing' as it is 'about' what the photographer wants to show us. 'In much the same way that the subject of painting was discovered to be painting, so the subject of photography was shown to be itself' (Solomon-Godeau 1981, 26).

The following examples are offered as evidence of some of the ways in which, under various conditions and circumstances, the photo-mechanical properties of the medium have produced a uniquely 'photographic' interpretation of the Things in Front of the Lens.

Early in the twentieth century, the work of photographers such as Steichen, Stieglitz, Strand and Weston demonstrated that, rather than being a liability, the 'photo-mechanical truthfulness' by which the process interprets, renders and depicts the Things in Front of the Lens was capable of producing beautiful - while uniquely 'photographic' - images. As Weston wrote $(1932,7)$, 'the inherent limitations and exclusive potentialities become equally important' (Figure 2). In other words, such images are beautiful, haunting or moving because they are photographs.

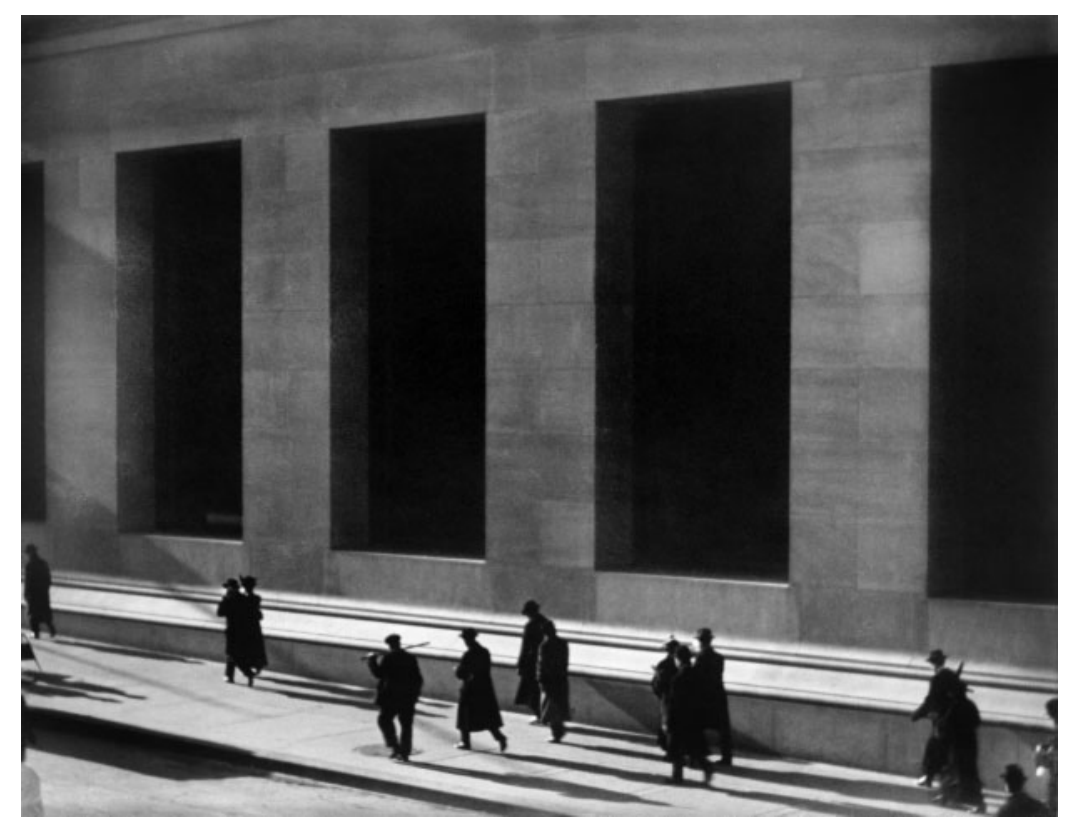

Figure 2. Wall Street, New York City 1915 - Paul Strand. 
Using their knowledge of the modus operandi of photography (including the capacity - in the examples reproduced above - to extract discreet 'slices' from what we experience as a chronological continuum), Cartier-Bresson, Kertész, Doisneau and many other photographers of le moment décisif documented 'moments' or events which did not and could not exist 'out there' - but which were instead produced by the act of photographing them (Figures 3 and 4).

Although such photographs are clearly not 'a faithful record of what has been witnessed' (Rogers 1978, 33) or describe things 'as they really are' (Ross 1982, 12) but depend on the 'contribution' of the photo-mechanical process in 'creating' the

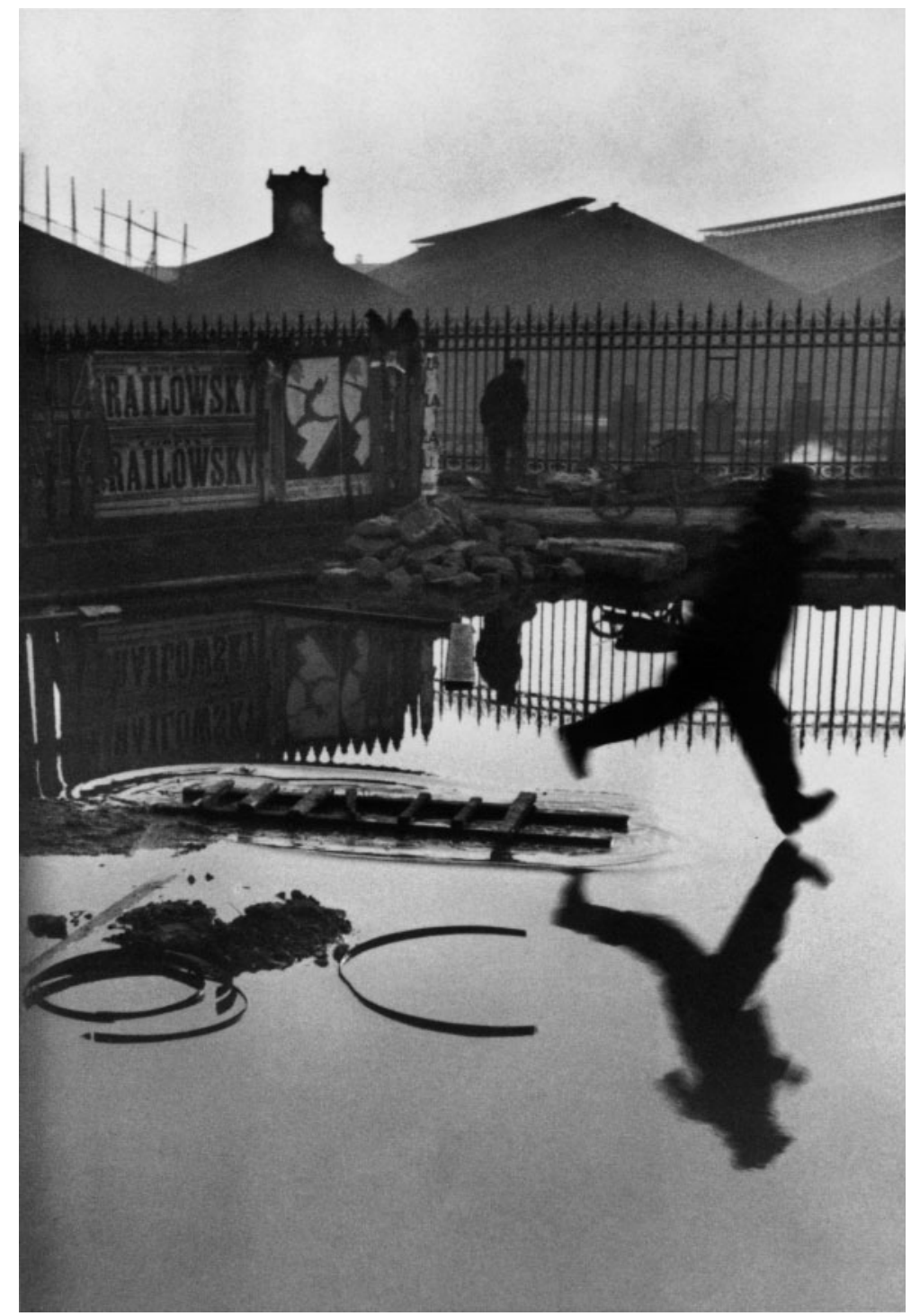

Figure 3. Derriere la Gare Saint-Lazare, Paris 1932 - Henri Cartier-Bresson. 


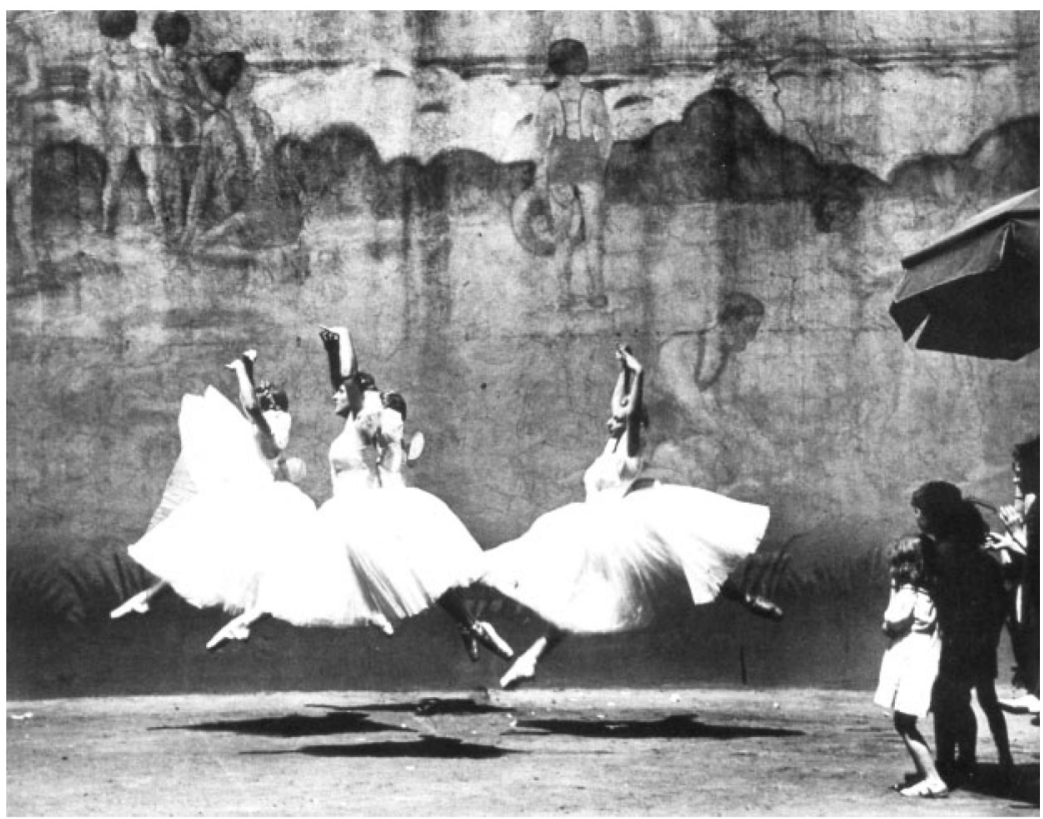

Figure 4. Ballet N.Y.C., 1938 C Estate of André Kertész/Higher Pictures

events they describe, it is worth noting that both Cartier-Bresson (quoted by Lyons 1966, 41) and Kertész (1985) repeatedly described their photographs as 'taken'.

In most photographs, the blur resulting from the motion of the camera during exposure would be deemed a 'flaw' or weakness. In Capa's series of photographs, however, this feature is understood to be the result of - and is therefore the photomechanical objective 'proof' of - the soldiers' (and Capa's) frantic efforts to get safely ashore on D-Day (Figure 5). This 'flaw' in the resulting record of the Things in Front of the Lens is therefore both the source of the 'truth' depicted in these images and the source of their power to affect us.

Exploiting our traditional faith in the photo-mechanical, 'objective truth' of the photograph and the 'reality' of what it shows, Halsman's surrealist trick delights us because, by being able to see through his construction, he has simultaneously fooled and not fooled us [like being tickled, which we 'know' is a mock attack, but which we 'pretend' that we do not Provine (2004); Figure 6]. Working with several studio assistants just outside the frame, Halsman has constructed and recorded a scene that is both real (the various elements were 'really there' in the unlikely positions in which his photograph has recorded them) - and surreal at the same time.

Like Cartier-Bresson and Kertész, Winogrand's work extracted moments from their chronological continuum (Figure 7). But where Cartier-Bresson, Kertész and others anticipated and used their knowledge of the way(s) in which the photographic process interprets and renders the Things in Front of the Lens, Winogrand allowed or invited - the 'unanticipatable' contribution of elements and process in the creation of the 'Moments' recorded/depicted in his photographs.

Frank explored the capacity of the photo-mechanical properties of the medium to produce images without the imposition of the conscious intent of the 


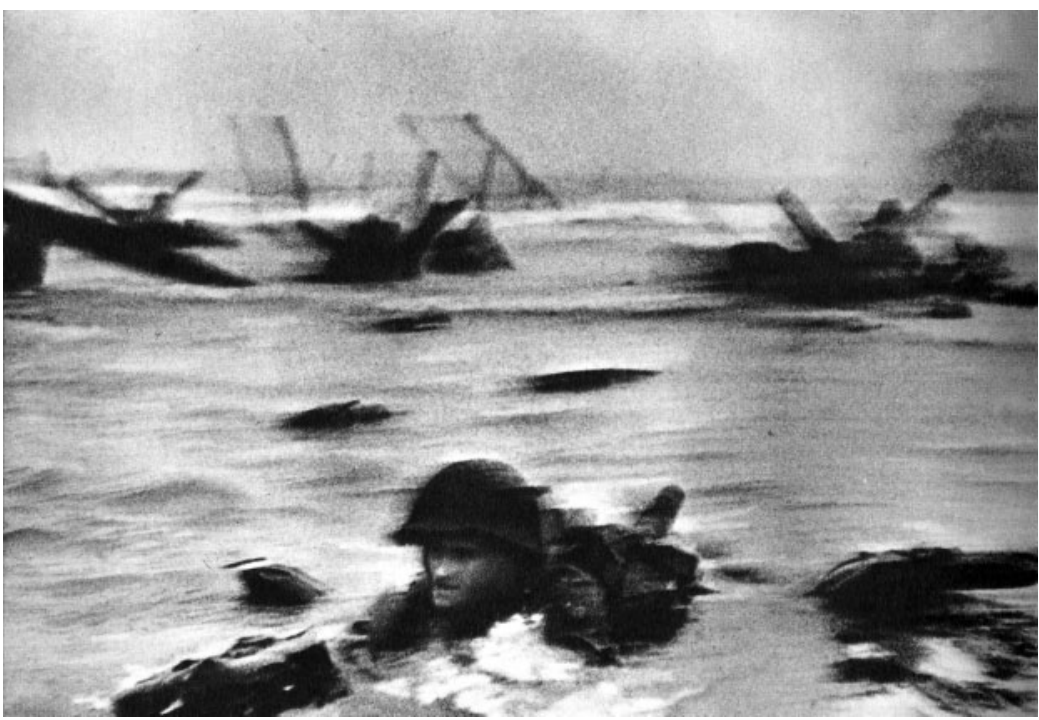

Figure 5. Allied landing on Normandy, 6 June 1944 - Robert Capa.

photographer - sometimes without even looking in the viewfinder. Frank's work poses the question: What happens when we point the camera at scenes and events and simply allow it to 'do its thing'? Despite this apparently collaborative way of working, however, Frank too, (quoted by Lyons 1966, 66) described his photographs as 'taken'.

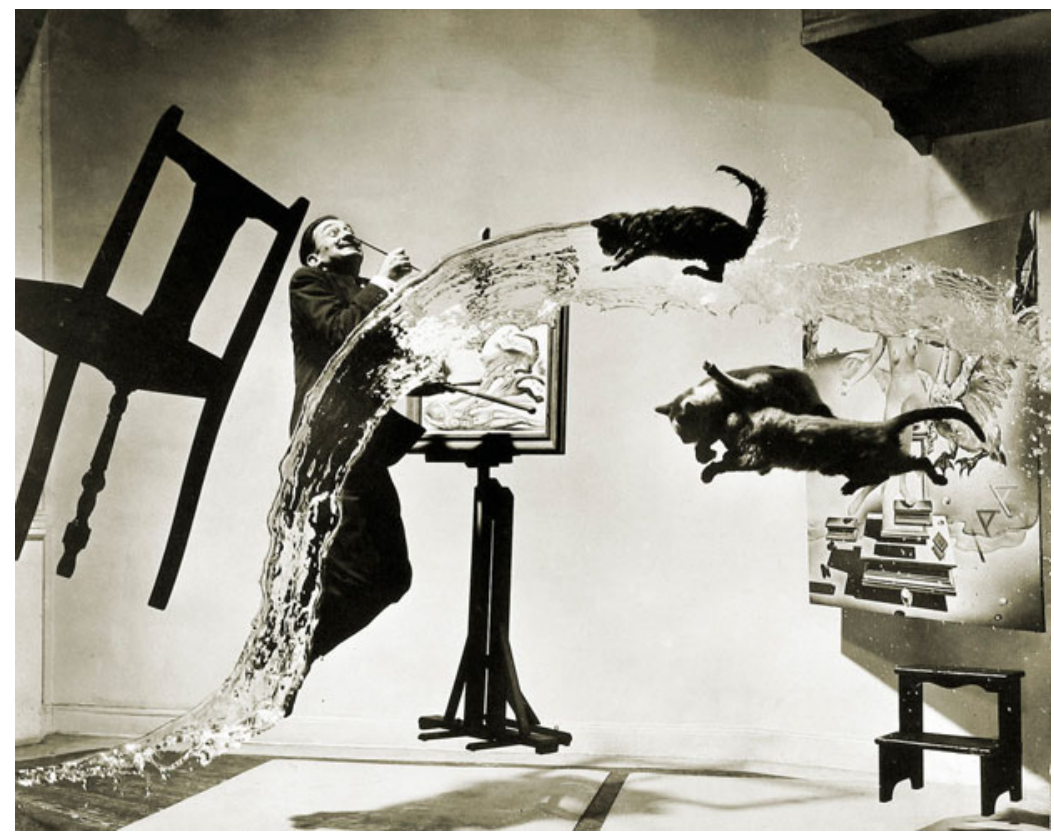

Figure 6. Dali Atomicus 1948 - Philippe Halsman. 


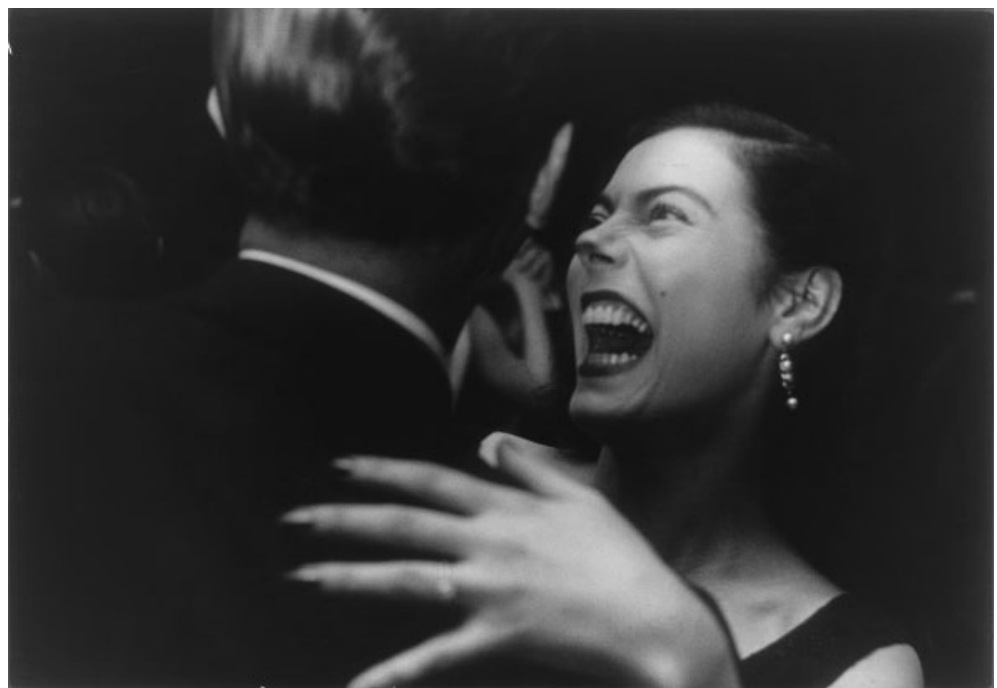

Figure 7. El Morocco 1955 - Garry Winogrand.

It is tempting to assume that Great $\mathrm{Art}^{\mathrm{TM}}$ is the product of, and therefore dependent on, the possession and application of Great Talent ${ }^{\mathrm{TM}}$. But imagine for a moment that a baby gets hold of a camera and, while bringing it to its mouth, accidentally pushes the button. Assuming that you were unaware of the origin of the image, imagine that, when looking at the resulting image, you find that it visually resembles a famous 'artistic' photograph. If you were then to learn the origin of the image, what does the knowledge that the creation of the image was not the result of the artist's intent do to your estimation of the 'value', quality or 'merit' of the resulting photograph? To what extent then, might a 'successful' photograph be independent of the application of talent or ability - and instead be the consequence of the medium just 'doing what it does'?

In Figure 8, Krzyzanowski anticipates and exploits the way in which the medium 'flattens' linear distance (which, had we been there beside him, we would have seen as three dimensions). As a result, Krzyzanowski has used (invited?) the medium to fundamentally re-contextualise the Things in Front of the Lens to create an image which could only have been made through photography.

Despite the explicit evidence that the image is composed of three separate exposures, Krzyzanowski has used our tendency to 'read' the composite image as a record of a single scene or event (Gestalt) and so has used photography to create (in
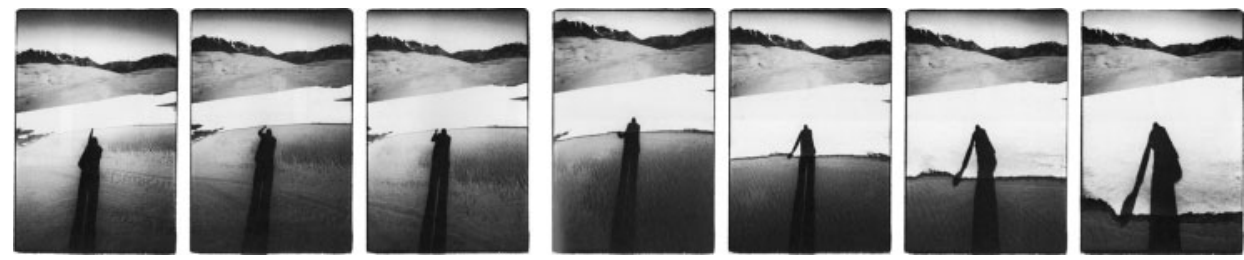

Figure 8. The Great Sand Dunes, November 1979 - C Michel Szulc Krzyzanowski, www.szulc.info. 

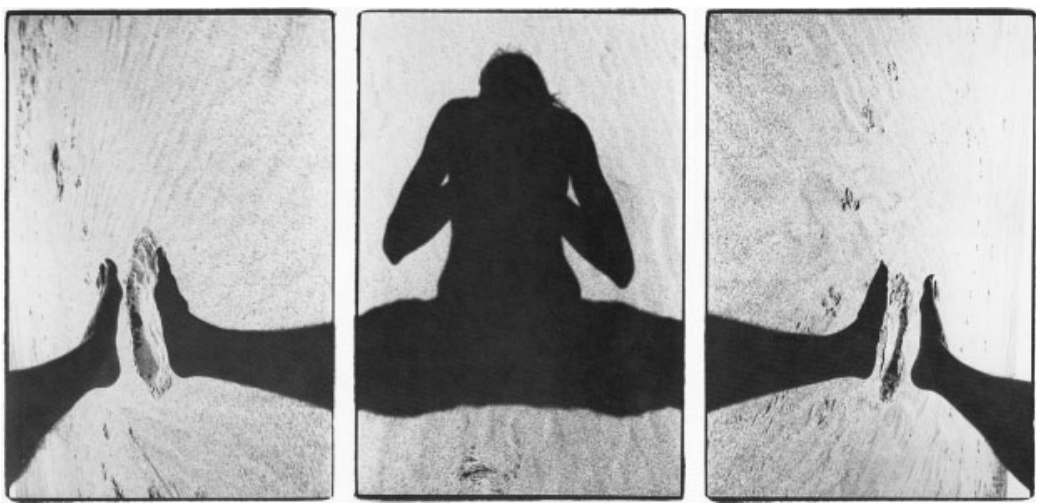

Figure 9. Baja California, 24 February 1980 - C Michel Szulc Krzyzanowski, www.szulc.info.

our imaginations) a faithful record of an event that did not exist 'out there' and so could not have been witnessed (Figure 9). Much more explicitly than many other photographers, the 'subjects' of Krzyzanowski's work are the medium of photography itself as well as the ways in which we are accustomed to 'making sense of' the way in which it interprets, records and renders the Things in Front of the Lens.

A body of work such as Krzyzanowski's must be understood as one expression of the profound alteration in our perception of what a photograph is [...] they create the event that the photograph records. (Solomon-Godeau 1981, 26-27)

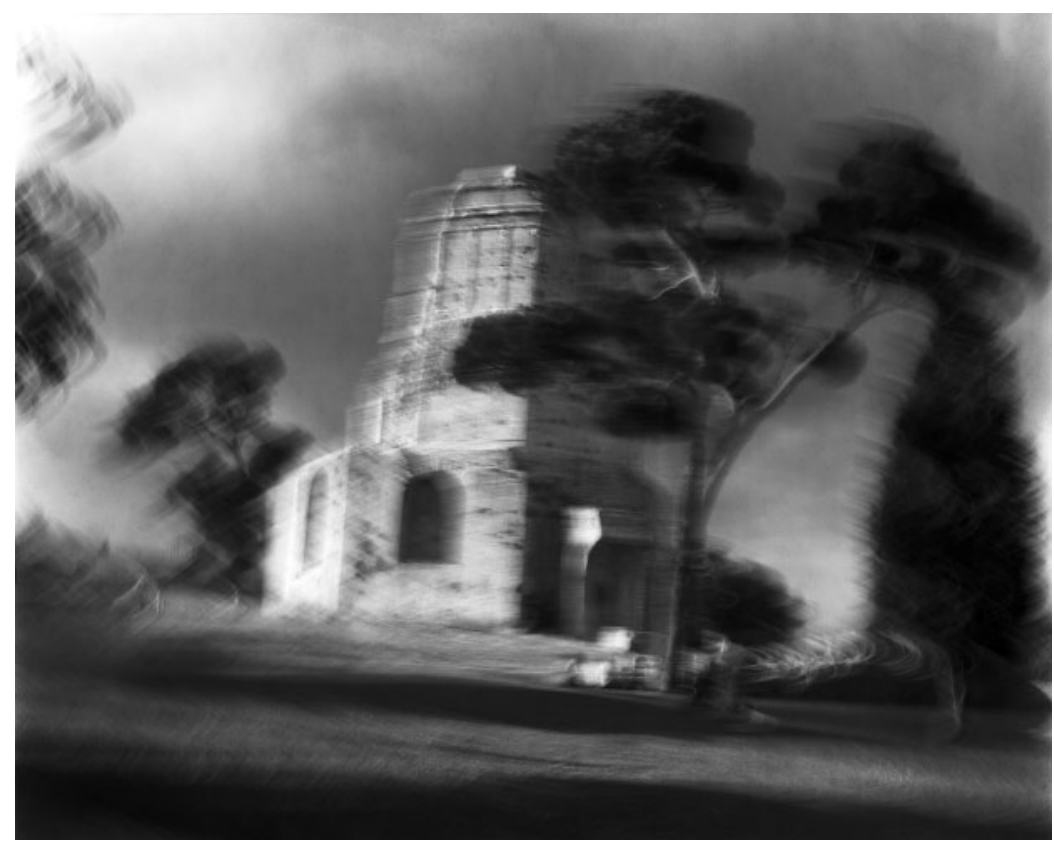

Figure 10. Tour Magne, Nimes 1979 - (C) Alex Neumann. 


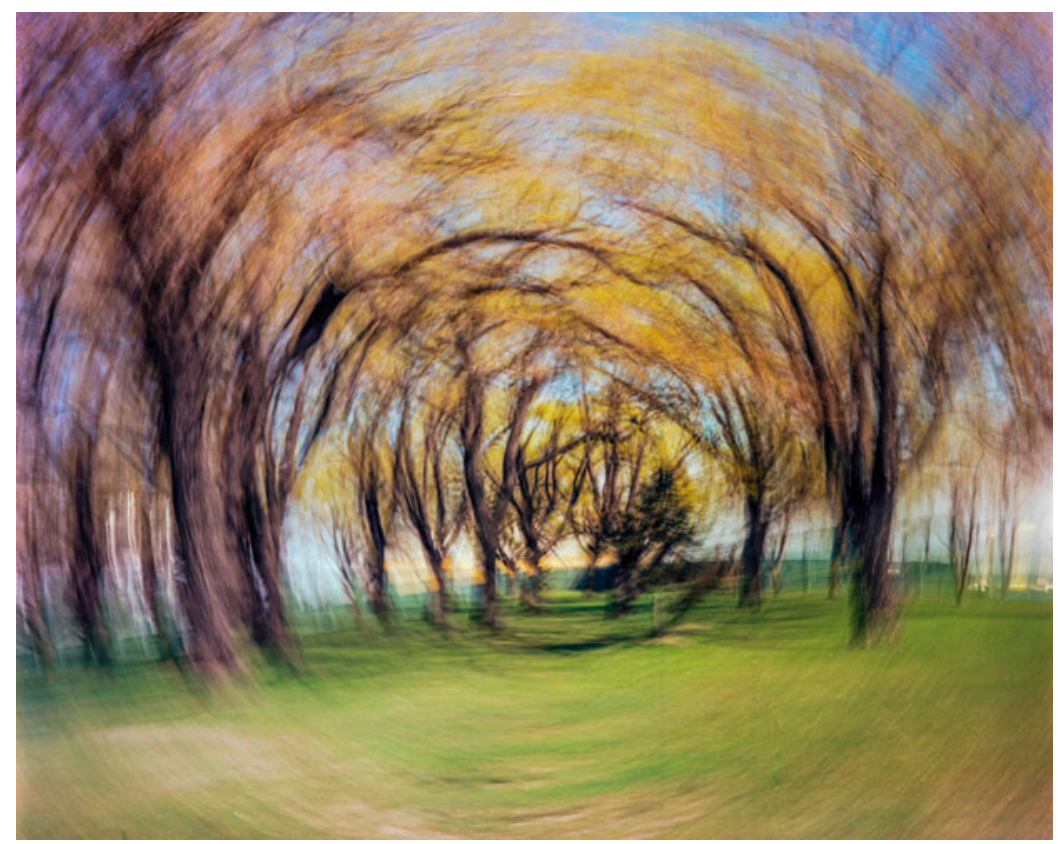

Figure 11. Trees, spring, Toronto Canada 1980 - (C) Alex Neumann.

In this series of photographs, Neumann explored the (unanticipatable) patterns and textures produced by the photo-mechanical process in response to the movement of the camera during the exposure (Figures 10 and 11). In describing the results, Neumann wrote: 'These images were created in the camera [based on] what the camera "saw" (personal correspondence, 2014).

- As evidenced by these and numerous other examples, I submit that:

- The affective power of many photographs is directly attributable to (and is often indivisible from) the way in which the process rendered and depicted the Things in Front of the Lens;

- As a consequence, these (and many other celebrated and eminent) images are 'about' photography and the way it 'IMAGinEs' or 'maps' the world as they are 'about' what the photographer wants to show us; and

- Both features are central to an indigenous photographic aesthetic.

\section{To create images and 'moments' that did not exist until photographed}

The following section describes three photographic projects by the author as evidence of an active (act of) contribution by the medium in the creation of scenes, events and moments which did not exist - and in some cases, could not have existed until created by the act of photography.

Based on my familiarity with the way in which the medium compresses and renders planes, the early photographs (1998-2000) were made in response to an intuitive attraction to various scenes, events and moments - but with neither a 
conscious intention to explore, nor an a priori belief in the active (act of) contribution of the medium. Instead, this conviction evolved gradually from the growing body of evidence in the photographs. Subsequent photographs in these series were made in a conscientious attempt to test and explore the hypothesis (that the medium is an active contributor in the resulting photographs) which evolved from a critical reflection on the accumulating body of evidence and an attempt to expand my understanding of the role of the medium in the creation of photographs.

The examples from these projects (available at http://www.theshadowofthe photographer.co.uk) are offered as evidence of the posited active (act of) contribution by the medium in the creation of uniquely 'photographic' images.

\section{The photograph as surface: reflections on planes}

To gain an alternative perception of events and their representation [for, as Huxley (1925) noted 'To know a thing in two languages is to know it better than in one'], in this series of photographs, I sought to explore the ways in which the camera 'sees' and 'maps' the world.

Photographs are two-dimensional descriptions of a world we know only through the perceptual and conceptual 'filters' of binocular vision. In giving us the means to experience both perspective and distance, our binocular vision has informed the mental symbols we use to 'map' and IMAGinE the world around us. [Put another way, 'the language of our eyes' has shaped 'the eyes of our language', and which in turn - pace Korzybski (1933/1994) defines not only what we know, but also how we 'know' it.]

We live in a world of space, depth, time and movement. Unlike our 'mental maps' which are the product of binocular vision, the camera describes the world as a surface because, with its monocular eye, this Cyclops sees it as one. Treating linear distance as an infinite series of layers or 'surfaces', the camera reveals patterns within (or hidden behind) what we experience as a three-dimensional world. In doing so, the medium records and depicts (and thereby makes visible to us) relationships in threedimensional space (as in that photo of Aunt Edna with the telephone pole protruding from the top of her head) that we often do not - or cannot - see.

Likewise, photography also depicts time differently because its definition of 'a moment' is different than our own. As a consequence of the mechanics of human cognition, we experience events as having a beginning, a middle and an end (Van Voorst 1988, 14); this, and the structure of our language with its bias towards describing events in terms of causes and effects [what, Enkvist, $(1995,123)$ called 'the epistemics of cause and effect'] means that we can rarely (if ever) accurately anticipate how the camera will 'see' and record an event or 'moment'.

Watts (1966, 26-27) explained:

Here is someone who has never seen a cat. He is looking through a narrow slit in a fence, and, on the other side, a cat walks by. He first sees the head, then the furry trunk, and then the tail. Extraordinary! The cat turns around and walks back, and again he sees the head, and a little later the tail. This sequence begins to look like something regular and reliable. Thereupon he reasons that the event head is the invariable and necessary cause of the event tail [...]. The narrow slit in the fence is much like the way in which we look at [and make sense of] life. 
By treating the linear distance we experience as three dimensions as an infinite succession of two-dimensional planes and then, by extracting discrete 'slices' from what we experience as a chronological continuum, the results of this project have shown that the camera 'sees' and records - and in doing so, sometimes creates relationships between planes and 'moments' not always visible to, or anticipatable by, a bino-chrono consciousness like ours (Figures 12 and 13). In an effort to learn to understand how the camera 'maps' the world, in undertaking this project, I have offered it scenes and materials (such as juxtaposed planes and reflections distorted in - and by - the topography of three-dimensional surfaces) whose beauty is apparent even to a poor 'bino' like me.

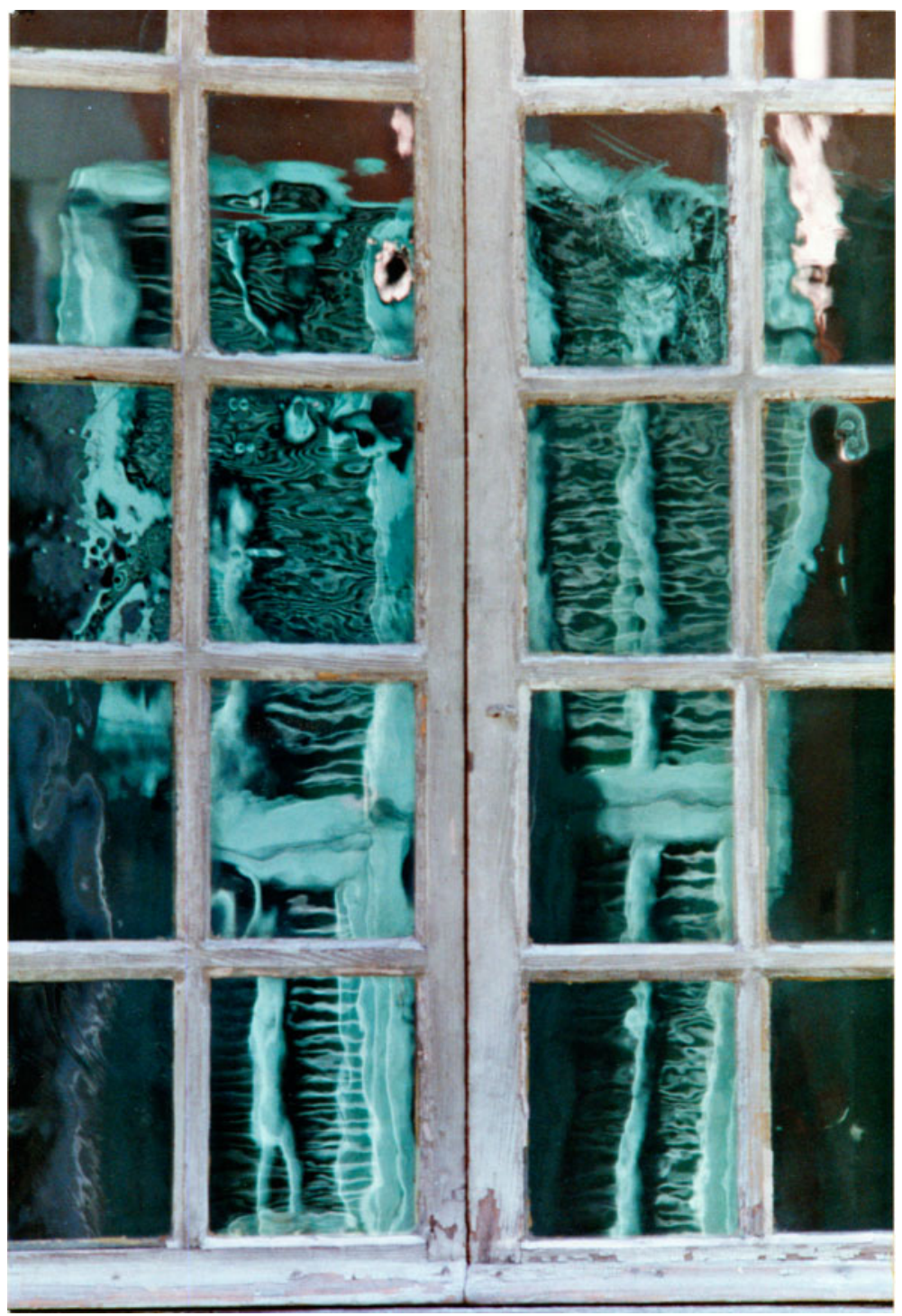

Figure 12. Green eyed monster, Nice 1998 - (C) Rutherford. 


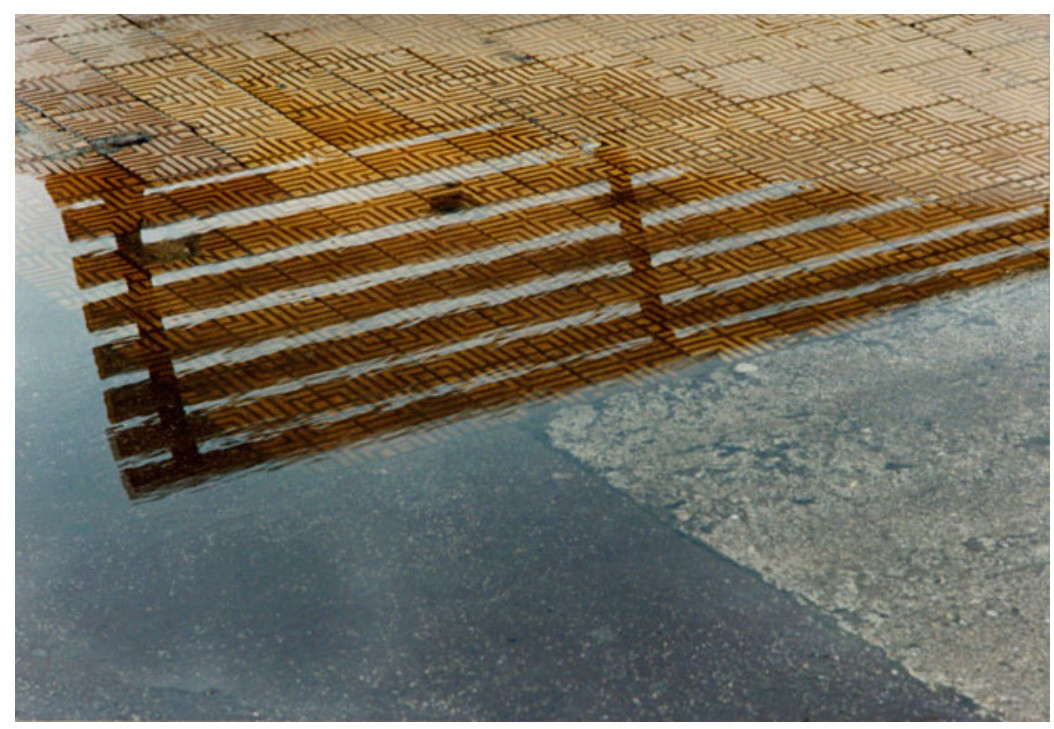

Figure 13. Promenade des Anglais \#3, Nice 2006 - (C) Rutherford.

These images may be an 'accurate and objective record' (Genoni 2002, 137) and a 'natural and truthful' account (Fosdick and Fahmy 2007, 1) - but one which depicts 'how things really were' to the camera, not to us. Simultaneously both the record and the product of a very different 'way of knowing', the scenes and 'moments' thus depicted did not - and sometimes could not - exist for us 'out there', but were made visible only by (what I have called) an act of photography.

Through this and the subsequent series, I have used the camera as a way to 'see through the fence' - and as a means to explore the world (or other worlds?) otherwise inaccessible to me through the perceptual filters imposed by my binochrono 'way of knowing'.

Extending the results of this project, in making the photographs in two subsequent projects (below), I introduced additional variables in an effort to further reduce the extent to which I was able to anticipate (and thereby exert control over) the final image - and thereby (I hoped) make more explicit the way in which the photographic process 'saw' and interpreted the Things in Front of the Lens at that instant and from that perspective.

\section{Bus paintings}

This project invites the unanticipable contributions of two additional players: the modus operandi of a basic digital camera (which, with its delay between the pushing of the button and the recording of the image, reduced my ability to exert selective control over the image recorded) and the sway (motion-through-time) of coaches, city buses, trains and hired cars (Figures 14 and 15).

\section{Submarines}

Also made using a range of digital cameras (which, again, reduced my ability to exert selective control over the image), this project introduced the reflective-refractive 


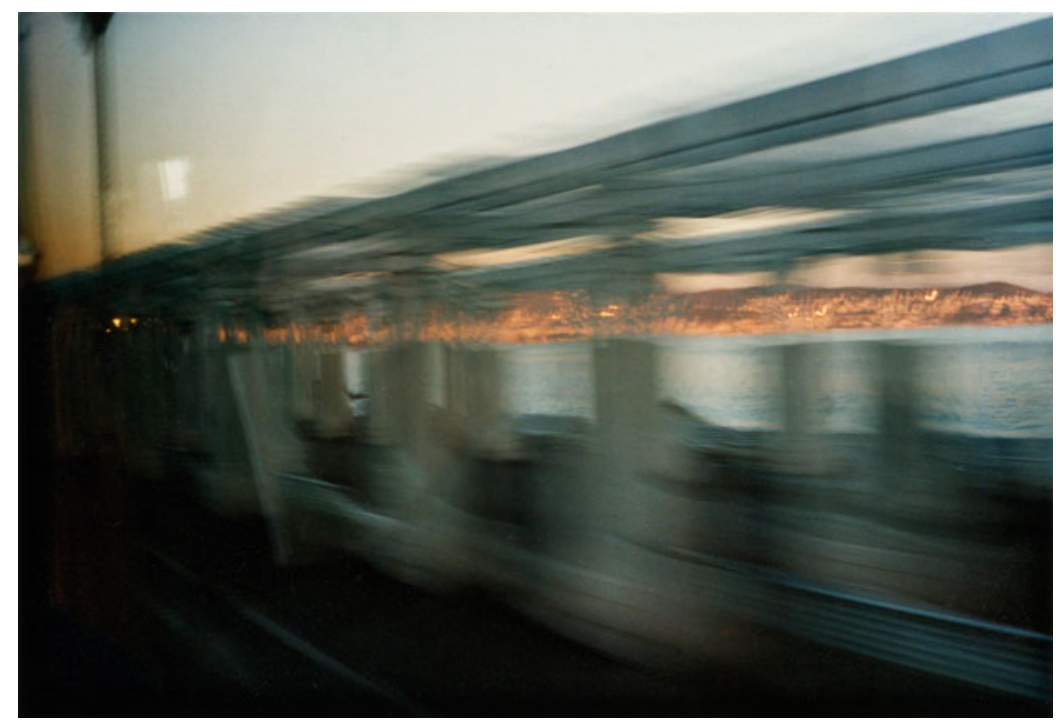

Figure 14. Sophia bus painting \#1, Promenade des Anglais 2003 - (c) Rutherford.

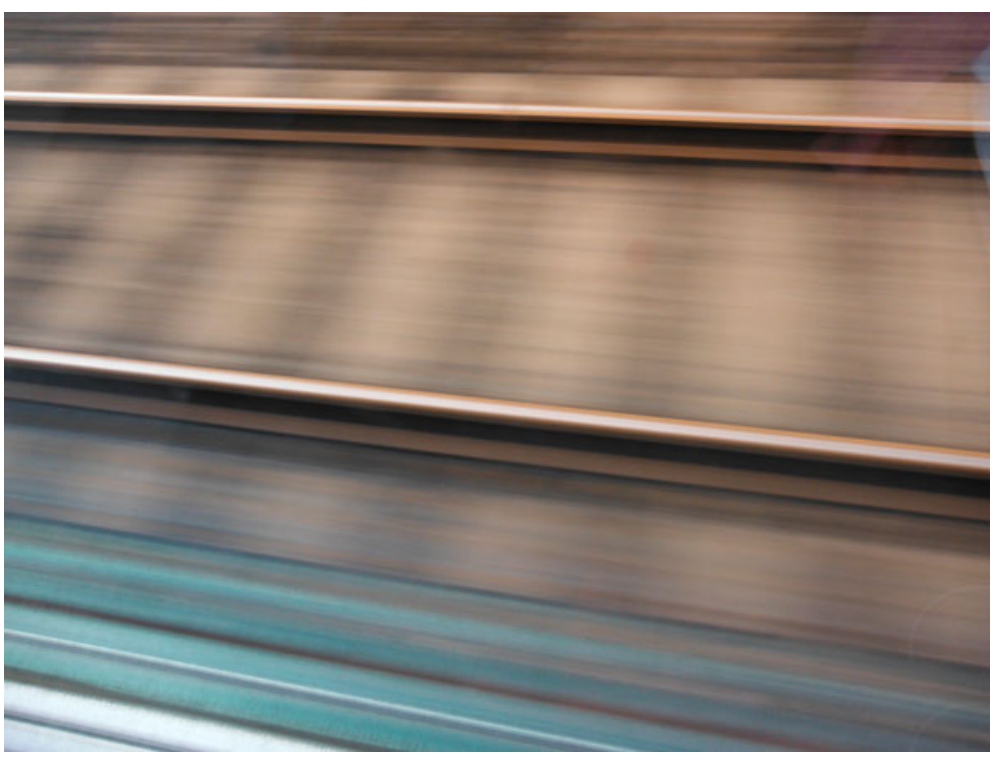

Figure 15. Train from Bournemouth 0452014 - (C) Rutherford.

properties of water - and the ways in which the photo-mechanical properties of the medium interpreted, flattened and rendered the resulting succession of twodimensional 'surfaces' - in the depiction of those who agreed to undergo the ordeal of posing for me (Figures 16 and 17). They, together with the medium and the water did all the work. I just pushed the button. 


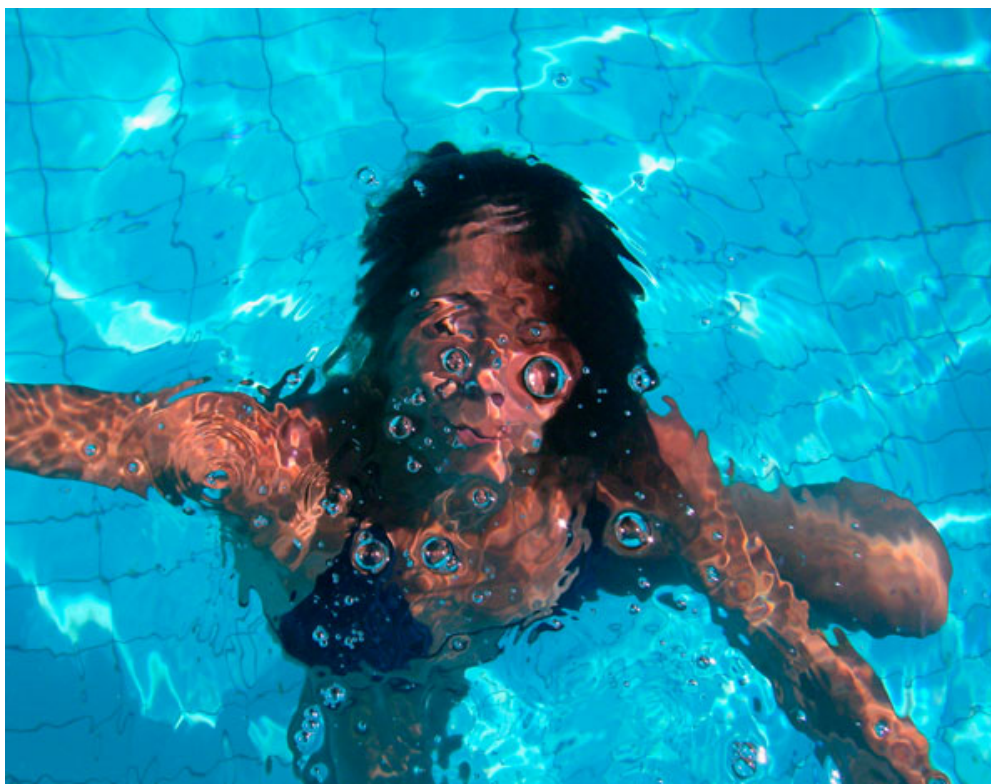

Figure 16. Syrigos Selini submarine 47832010 - (C) Rutherford.

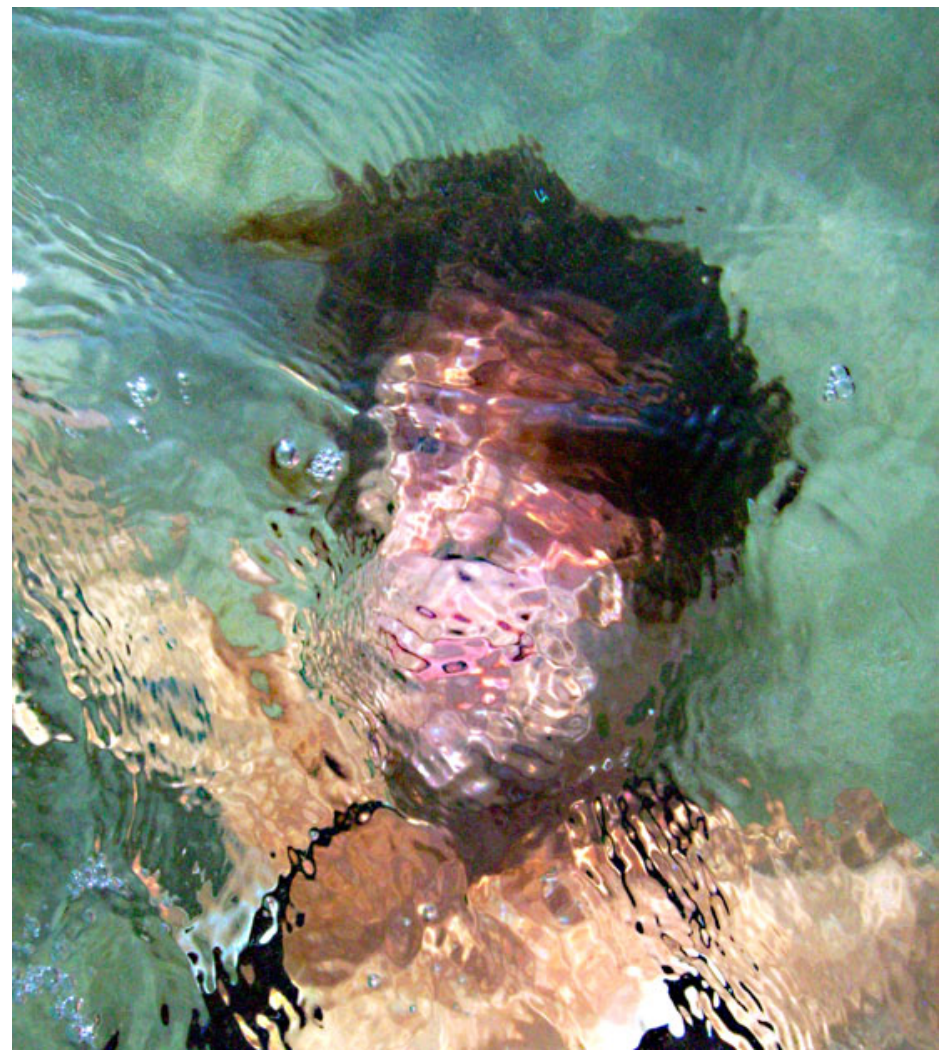

Figure 17. Cretan Sea submarine 03032013 - (C) Rutherford. 


\section{To offer our subconscious an unmediated means of expression}

Everyone who has a camera makes two different kinds of photographs: those of scenes and events (such as birthday parties and holidays) with which we have a conscious connection. The second are those scenes, events and 'moments' with which we have no personal association but which appealed to us just because we liked the way something looked - often without knowing why our attention/interest was attracted to that particular scene. For example, we might 'decide' to photograph children playing in a park, an old house or a bicycle lying in the grass - but we do not know those children, or the people who lived in that house - and that is not our bicycle.

Through a combination of grounded theory supported by extensive reading of the works of Jung, the following project attempted to explore both the reasons for and the implications of our (largely intuitive) attraction to those scenes, events and 'moments' we are drawn to record.

\section{The shadow of the photographer}

Between professional assignments while working (1982-1993) as a commercial photographer, I continued to make photographs for personal projects. In what was probably a reaction to the fastidious degree of control over my compositions demanded by clients (and their art directors), when making photographs for these personal projects, I sought to avoid imposing on my pictures the 'rules of good photographic composition' I had been taught and instead, relying only on my intuition to select the scene, frame the image and choose The Moment, exploited the camera's ability to record images at the touch of a button. Ultimately, (taking a clue from Robert Frank), I stopped looking in the ground glass of my twin lens Rolleiflex before releasing the shutter.

To my surprise, in several of the resulting photographs, I began to recognise metaphorical descriptions of aspects of my Self I had been unable (or unwilling) to acknowledge - what Jung called my Shadow. Like a flashbulb that briefly illuminates a dark street and which reveals the goings-on in the shadows only after developing the film, in the scenes and events I had 'chosen' to record, I found picture postcards of the emotional landscape I inhabited 'in here' - as well as allegorical self-portraits of the one I had become in my effort to find a way through it.

The discovery that an intelligence so clearly intimate with my most frightening secrets should not only possess the ability to make itself heard - but also to address itself to subjects I had effectively banished from the court of conscious awareness, shook me like a blow. It was as if others could hear the private voices of reproach and self-doubt that rang incessantly in my ears. This was my first hint that the medium can be more than an obedient tool under the conscious control of the operator.

In an effort to discover whether anyone could use photography in this way, I organised a series of workshops (2000-2005) in which a total of 200+ participants (French MBA students with no prior training in either photography or psychology) were asked to carry a small, portable camera with them wherever they went and to photograph those scenes and events to which they felt an intuitive response (a 'tap on the shoulder'). Participants were asked not to 'think about' composition or framing, but to allow their intuition to determine the arrangements of the elements within the frame as well as the moment at which it 'felt right' to release the shutter. 
In preparing the materials for these workshops, I consulted with Mr Bruce C.S. Barnes of the Ontario (Canada) Association of Jungian Analysts:

I consulted with Rutherford as he developed the process of using photography as a means to identify the contents of the unconscious. He has incorporated Jung's model of the psyche in relation to photography and demonstrated a thorough understanding of Jung's concepts and foundational ideas. He has also applied them in a way that enhances our understanding of Jungian psychology, while offering a new perspective on photography. (personal correspondence, 2002)

At the end of 10 weeks, participants were asked to leaf casually ('absent mindedly') through their photographs, and identify those at which they regularly and instinctively paused. In interpreting their photographs, they were encouraged to approach each image as a dream fragment and to look for clues in both the individual symbols within it, as well as in the 'story' it seemed to tell. Participants were asked to consider carefully the context of the picture and not just its individual elements, as well as their situation at the time that the photograph was made. It was suggested that, while it is often easy to misinterpret a single image, by examining groups of photographs to which they had responded, they may find clues in any recurring themes or motifs. Participants were warned to be wary of the tendency to 'see what they would like to see'.

Participants were then asked to reflect on six of their photographs, to identify the symbols or symbolic relationships they believed they had recognised within each and to explain the significance or the meaning (if any) they found within them.

This project has been very interesting to do. I must admit that at the beginning I was sceptical; I wasn't convinced that we could analyse our own pictures. Now I know it's possible. It has helped me to realise where my problems are. It has set things in my mind and I've understood a lot of things. I can't hide that I've got tears in my eyes right now. I think that is the magic of photography. Now I'm convinced that our pictures reflect our souls, and that must be the conclusion of the course. (Comment by workshop participant 2001)

Based on my own long-term project (1982-1998) and the results of more than 200 participants in these workshops (2000-2004), the accumulated evidence indicates that the medium of photography offers our subconscious mind a means of unmediated expression.

By providing us with an instantaneous ('point and shoot') means to record those scenes, objects, events and moments 'out there' to which our attention was intuitively drawn, and to record these without the requirement - or interference - of judgements as to what constitutes a 'good' photograph, the camera enables us to capture allegorical depictions of our intuitively recognised 'mental maps': illustrations of the way in which we IMAGinE the world 'out there' - and, sometimes, allegorical selfportraits of the way in which we IMAGinE ourselves 'in here'.

In the juxtaposition of the visual elements within the scene, we may have intuitively recognised an allegory for something below the horizon of our conscious awareness to which, with a subliminal tap on the shoulder, our unconscious is now trying to bring to our attention. In the image of children playing happily together, we may find a metaphor for the acceptance by others that we so desperately seek; a dark 
and empty house may represent the painful memory of having been hurt, ignored or unloved at home, and the image of an abandoned bicycle may remind us of a father who was never there.

In the features of a pleasant landscape, we may recognise an allegory for the life we once dreamt of when our happiness did not depend on material possessions, power or status. Our photograph of a busy city street may suggest to us the path we chose instead - and include a clue as to what we left behind. And in the image of a figure surrounded by dark and foreboding shapes, we may find a clue to the fears and anxieties which, ever since, have threatened to control our lives. The photograph of a mannequin in a shop window may describe the circumstances in which we now feel trapped, and in another, the mask we have adopted in the hope of being accepted by others and which we may even have come to believe is the person we are underneath.

The results of this research have demonstrated that, due to the ability of the photographs to capture the details of scenes, objects, events and 'moments' without the need for - or the interference of - conscious decisions about what makes 'a good picture', the mantic patterns we are therefore able to record provides us with the means to represent our interior emotional terrain. These, in turn, provide us with a means to identify and reflect upon the private myths (the 'mental maps') through which we define our Selves, plot our course and live our lives.

These findings not only extend the application of the posited 'act of collaboration' with the medium, but, I believe, have significant implications for the selfknowledge of practitioners.

\section{Conclusion}

By challenging our current definition of the parameters of the role of the photographic medium in the creation of images, I believe we can discover new ways of thinking about what it is that photographs (as well as the results of other photo-mechanical media) show us.

By acknowledging the unique perspective of our technological 'partners' and by welcoming the 'point of view' afforded by their modus operandi as active contributors in the creation of our work, we may find new ways to explore what is 'out there' and through these discover (uncover?) phenomena which, due to the limits imposed by our current definitions, are currently invisible.

\section{Disclosure statement}

No potential conflict of interest was reported by the author.

\section{Notes}

1. In this article, I am concerned only with the photograph as the product of the camera and the photo-mechanical process, not with its social or cultural significance, and so I have not considered the role of the viewer.

2. I use this typographical configuration as a reminder that the root of the verb 'to imagine' is image. 


\section{Notes on contributor}

An illustrative photographer in Toronto, Canada from 1982 to 1993, Rutherford made photographs for advertising, public relations and corporate communications campaigns. Since withdrawing from commercial practice, Rutherford has been Senior Lecturer in Culture and Communication at EAI/CERAM in Sophia Antipolis, France (1999-2005) and Programme Leader of BA Advertising at the University of Chester (2005-2014). Rutherford is now Senior Lecturer in Creative Advertising at Bournemouth University. Rutherford's photographs have been exhibited in Canada, the USA, France, New Zealand and Japan. Rutherford's website: http://www.theshadowofthephotographer.co.uk/

\section{References}

Alvesson, M., and K. Sköldberg. 2009. Reflexive Methodology: New Vistas for Qualitative Research. London: Sage.

Arbus, D. 1972. Diane Arbus. New York: Aperture.

Barthes, R. 1984. Camera Lucida: Reflections on Photography. New York: Hill \& Wang.

Bordieu, P. 1993. Sociology in Question. Translated by R. Nice. London: Sage.

Boulding, K. 1961. The Image: Knowledge in Life and Society. Ann Arbor: University of Michigan Press.

Bourdieu, P. 1996. Photography: A Middle-brow Art. Stanford: Stanford University Press.

Bryman, A. 2012. Social Research Methods. Oxford: Oxford University Press.

Crimp, D. 1980. The Photographic Activity of Postmodernism. October, Vol. 15 (Winter, 1980), pp. 91-101.

de Brigard, E. 1995. "The History of Ethnographic Film." In Principles of Visual Anthropology. 2nd ed., edited by Paul Hockings, 13-43. New York: Mouton de Gruyter.

Diamonstein, B. 1981-1982. An Interview with Garry Winogrand. Visions and Images: American Photographers on Photography. New York: Rizoli. Accessed October 28, 2012. http://www.jnevins.com/garywinograndreading.htm.

Dion, D. 2007. "The Contribution Made by Visual Anthropology to the Study of Consumption Behavior." Recherche et Applications en Marketing 22 (1): 61-78.

Enkvist, N. E. 1995. "The Epistemic Gap in Linguistic Stylistics." In On Languages and Language. Presidential Addresses of the 1991 Meeting of the Societas Linguistica Europaea. Trends in Linguistics, Vol. 78, edited by Werner Winter, 109-126. Berlin: Studies and Monographs.

Fosdick, S., and S. Fahmy. 2007. "Epistemic Honesty and the Default Assumption that Photos Are True." SIMILE: Studies in Media \& Information Literacy Education 7 (1): $1-10$.

Fox Talbot, W. H. 1844. The Pencil of Nature. London: Longman, Brown, Green and Longmans.

Genoni, P. 2002. "The Photographic Eye: The Camera in Recent Australian Fiction." Antipodes 16 (22): 137-141.

Gernsheim, H. 1965. A Concise History of Photography. London: Thames \& Hudson.

Gray, C., and J. Malins. 2004. Visualising Research: A Guide for Postgraduate Students in Art and Design. Aldershot: Ashgate.

Grenfell, M. I., and D. James. 1998. Bourdieu and Education: Acts of Practical Theory. London: Falmer Press.

Harris, J. 2006. Art History: The Key Concepts. Abingdon: Routledge.

Hayakawa, S. I. 1949. Language in Thought and Action. New York: Harcourt-Brace.

Huxley, A. 1925. Those Barren Leaves. New York: Avon.

Kertész, A. 1985. Kertész on Kertész. London: BBC.

Korzybski, A. 1933/1994. Science and Sanity - An Introduction to Non-Aristotelian Systems and General Semantics. 5th ed. Brooklyn: Institute of General Semantics.

Krauss, R. 1984. A Note on Photography and the Simulacral, October, Vol. 31 (Winter, 1984), 49-68.

Lyons, N. ed. 1966. Photographers on Photography: A Critical Anthology. Englewood Cliffs: Prentice Hall. 


\section{Rutherford}

Marder, E. 2012. The Mother in the Age of Mechanical Reproduction: Psychoanalysis, Photography, Deconstruction. New York: Fordham University Press.

Mellinger, W. M. 1994. "Towards a Critical Analysis of Tourism Representations." Annals of Tourism Research 21 (4): 756-779.

Moran, M. J., and D. W. Tegano. 2005. "Moving toward Visual Literacy: Photography as a Language of Teacher Inquiry." ECRP 7 (1). Accessed October 3, 2014. http://ecrp.uiuc.edu/ v7n1/Moran.html.

Price, D. 2000. "Surveyors and Surveyed: Photography Out and About." In Photography: A Critical Introduction, edited by L. Wells, 65-118. Oxon: Routledge.

Provine, R. R. 2004. "Laughing, Tickling, and the Evolution of Speech and Self." Current Directions in Psychological Science 13 (6): 215-218.

Rogers, B. 1978. "Photography and the Photographic Image." Art Journal 38 (1 Autumn): $29-35$.

Rose, G. 2006. Visual Methodologies. London: Sage.

Ross, S. 1982. "What Photographs Can't Do." Journal of Aesthetics and Art Criticism Vol. 41 (1 Autumn, 1982): 5-17. doi:10.2307/430819.

Seamon, R. 1997. "From the World Is Beautiful to the Family of Man: The Plight of Photography as a Modern Art." Journal of Aesthetics and Art Criticism 55 (3 Summer): 245-252. doi:10.2307/431795.

Silverman, D., ed. 2010. Qualitative Research. 3rd ed. London. Sage.

Smith, C. 1999. "Fragmented Documents: Works by Lorna Simpson, Carrie Mae Weems, and Willie Robert Middlebrook at the Art Institute of Chicago." Art Institute of Chicago Museum Studies 24 (2): 245-272.

Solomon-Godeau, A. 1981. "Photographing the Photographic." Photo Communique, Summer: 26-30.

Sontag, S. 1973. On Photography. New York: Farrar, Straus and Giroux.

Stylianou-Lambert, T. 2012. "Tourists with Cameras - Reproducing or Producing." Annals of Tourism Research 39: 1817-1838.

Urry, J. 2002. The Tourist Gaze. Los Angeles, CA: Sage.

Van Voorst, J. 1988. Event Structure. Current issues in linguistic theory, Vol. 59. Philadelphia: John Benjamins.

Watts, A. W. 1966. The Book on the Taboo against Knowing Who You Are. New York: Collier Books.

Weston, E. 1932. The Art of Edward Weston. Edited by M. Armitage. New York: E. Weyhe. Whorf, B. L. 1952. "Language, Mind and Reality." ETC: A Review of General Semantics 9: 3. 